\title{
A comparative assessment of generalized anxiety, conduct and peer relationship problems among AIDS and other orphaned children in India
}

Prem Kumar SG*, Anil Kumar G, Ramgopal SP, Venkata Srinivas V and Rakhi Dandona

\begin{abstract}
Background: Data on mental health among orphaned children in India are scanty. We compared the generalized anxiety, conduct and peer relationship problems and their associated risk factors among children orphaned by HIV/ AIDS and those due to other reasons in the Indian city of Hyderabad.

Methods: Four hundred orphaned children aged 12 to 16 years residing in orphanages in Hyderabad were sampled, half being AIDS orphans (COA) and the rest orphaned due to other reasons (COO). Interviews were done using standardized scales to assess generalized anxiety, conduct and peer relationship problems. A score $>8,>4$, and $>5$ was considered as indicator of generalized anxiety, conduct problem and peer relationship problem, respectively. Variations in the intensity of these three conditions due to possible factors including co-existing depression were assessed using multiple classification analysis (MCA).

Results: A total of 396 (99.3\%) orphans participated of whom 199 (50.3 \%) were COA. The mean generalized anxiety, conduct and peer relationship problem scores were 11.1 (SD 5.2), 3.8 (SD 2.5) and 3.8 (SD 2.5) for COA; and 7.6 (SD 4), 2.6 (SD 2) and 2.3 (SD 1.8) for COO, respectively. Among COA, the prevalence of generalized anxiety score of $>8$ was $74.4 \%$ (95\% Cl 67.8-80.0\%), of conduct problem score of $>4$ was $33.2 \%$ (95\% Cl 26.9-40.1\%), and of peer relationship problem score of $>5$ was $27.6 \%$, (95 \% Cl 21.8-34.3\%), with these being significantly lower in COO. In MCA, a higher mean depression score had the highest effect on the intensity of generalized anxiety, conduct and peer relationship problem (Beta 0.477; 0.379 and 0.453 respectively); being COA and a girl had the most impact on generalized anxiety (0.100 and 0.115 , respectively).

Conclusions: A significantly high proportion of AIDS orphans deal with generalized anxiety, conduct and peer relationship problem as compared with other orphans highlighting the need to address the poor mental health of orphans in India.
\end{abstract}

Keywords: AIDS, Generalized anxiety, Children, Conduct problem, HIV, India, Mental health, Orphans, Peer relationship problem

\footnotetext{
*Correspondence: kumarsg.prem@gmail.com

Public Health Foundation of India, Plot 47, Sector 44, Gurgaon 122 002, India
} 


\section{Background}

With the recent adoption of draft mental health bill by the government of India, mental health is slowly gaining attention as a priority in India among the policymakers [1]. It is estimated that up to $40 \%$ of HIV infected children are orphaned in India but little is known about their mental health consequences [2]. Mental health issues related to HIV/AIDS among young people, orphans and for those caring for orphans are well recognized globally, including depression, generalized anxiety, conduct and peer relationship problems, however, majority of the evidence comes from Africa [3-16]. Previous studies among Indian children have highlighted co-morbid conditions in children with depression to include anxiety and conversion/ dissociative disorder [17], and the prevalence of anxiety disorder was reported to be $18 \%$ in children infected with HIV [17]. We have recently reported the prevalence of depression to be $84.4 \%$ among HIV orphaned children in Hyderabad from southern India [18].

In countries where local data are not available to help guide national policies to address the health issues of orphans and vulnerable children affected by HIV/AIDS, the UNAIDS recommends to replicate successful interventions that were implemented elsewhere [19]. With one or both parents dead for an estimated $5 \%$ of the over 400 million children in India [20, 21], there is a strong need for mental health interventions targeting the orphans and vulnerable children irrespective of the cause of parental death. In this paper, we provide comparison of generalized anxiety, conduct and peer relationship problems among children orphaned by HIV/ AIDS and those orphaned due to other disease/conditions to contribute to building local evidence to guide relevant policies and programs.

\section{Methods}

We conducted a mental health study among orphaned children during January to March 2012 in 14 orphanages in and around Hyderabad city in southern India. The ethics approval for this study was provided by the Ethics Committee of the Public Health Foundation of India, New Delhi. Provision was made for referral to a psychologist if a child felt emotionally disturbed following the interview.

Detailed methodology for this study has been reported previously [18], and methods of relevance are presented here. We sampled children orphaned due to HIV/AIDS (COA) and those orphaned because of reasons other than HIV/AIDS (COO) aged 12 to 16 years. An orphan child was defined as a child who had lost one or both parents, and therefore included maternal, paternal, and double orphans [22]. A total of 14 orphanages having at least 20 orphaned children in the ages 12 to 16 years were sampled, and these together housed 524 orphaned children. Of these, two orphanages were run by the Government of the Indian state of Andhra Pradesh and the remaining 12 by private non-government organisations (NGOs). A total of 6 orphanages housed $\mathrm{COO}$ and 8 orphanages housed exclusively COA. Assuming $80 \%$ power to detect a $10 \%$ difference in mental health outcomes of interest between AIDS and other orphans at the $95 \%$ confidence level (95\% CI 3.5-16.5\%), using the unpooled method we estimated a total sample size of 167 children from each among COA and COO. We utilized proportional sampling technique to maintain adequate representation of the $\mathrm{COO}$ to their estimated number available at each orphanage. However, we sampled all available eligible COA as the numbers of these children were not enough. The children aged 12-16 years who had spent at least 6 months at the orphanage and who could understand at least one of the three languages - Telugu, Hindi or English were considered eligible for the study.

Each potential participant was contacted by an interviewer trained in the study procedures with the assistance of the orphanage staff. The study was explained and informed consent sought for participation. For children aged 12 to 14 years, child assent and the consent from the concerned care-giver/guardian was obtained; and written informed consent was provided by children 15-16 years of age. All participants had the right to refuse participation or stop interview anytime. Before starting interview, each participant was narrated a short and simple story to assist the child to understand the context and content of the interview. This story was developed with inputs from a mental health expert with experience in dealing with children. After this narration, the interview was conducted in privacy. Average interview time was $45 \mathrm{~min}$, and each participant received a nominal gift as a token of appreciation for their time at the end of interview.

The interview documented demographic characteristics of children including age, sex, education, religion, type of orphan, and duration of stay in orphanage. Mental health related measures documented relevant to this paper included generalized anxiety, history of abuse, violence and discrimination and conduct and peer relationship problems. History of abuse and violence by friends or relatives including type of abuse (denial of food, healthcare and other essential needs, denial of financial or property inheritance, physical and emotional abuse and sexual abuse), experience of abuse in the orphanage (denial of basic needs such as food and shelter, verbal abuse, threat of violence, physical beatings, sexual and mental abuse), and witnessing fights between parents was documented. History of experience of discrimination from friends/relatives and community were also documented. 
We used the generalized anxiety domain of the Spence Children's Anxiety Scale (SCAS) which is designed to assess general anxiety for children aged 8 to 15 years [23-25]. The respondents were asked to rate the degree to which they experienced each general anxiety symptom on a 4-point frequency scale (never, sometimes, often, and always). The possible scores ranged from 0 to 18 , and score higher than 8 indicates elevated levels of generalized anxiety [23-25]. The Strengths and Difficulties Questionnaire (SDQ) which is designed to assess behavioural disorders in children aged 5 to 17 years was used to document conduct and peer relationship problems [26-30]. The respondents were asked to rate the degree to which they experienced each symptom on a 3-point frequency scale (not true, somewhat true, and certainly true). The possible scores ranged from 0 to 10 . A score of 4 is considered borderline and that between 5 and 10 is considered abnormal for conduct problem; and a score of 4-5 is considered borderline and score between 6 and 10 is considered abnormal for peer relationship problem [26-30]. Both the scales were translated into the local languages for use, and then were back-translated and fieldtested to ensure proper readability. As cultural validity was a major concern in translating this scale, the researchers closely collaborated with mental health experts, child counselors and the NGO/orphanage staff to achieve accuracy of cultural understanding and translation for these scales.

Four rounds of pre-testing of the entire study instrument were undertaken among orphaned children aged 12-16 years prior to the study by the study investigators in consultation with a psychologist who worked with children. Inputs from the mental health experts, child counselors and the NGO/orphanage staff were obtained to refine and validate these for the study population. Based on these exercises, certain definitions were simplified, revisions in local language translation for Hindi and Telugu were made, and interview techniques improved.

SPSS version 17.0 was used for data analysis. Descriptive statistics for generalized anxiety, and conduct and peer relationship problem scores are reported for relevant variables, and independent sample $\mathrm{T}$ test and ANOVA test were used to assess significance as appropriate [31]. We used the Tukey post-hoc test for independent variables with more than two categorical groups to assess which groups differed from each other [32]. The association of generalized anxiety score with depression, conduct and peer relationship problem score is presented separately for $\mathrm{COA}$ and $\mathrm{COO}$; and these scores were compared using the bivariate regression types available in Microsoft Excel (linear). We report the prevalence of generalized anxiety score $>8$, conduct problem score $>4$, and peer relationship problem score $>5$ among these children, which are the clinical cut-off scores in western settings [23-30]. Multiple classification analysis (MCA) was performed to assess the variation in intensity of anxiety, and conduct and peer relationship problems with select factors including depression which we have previously reported [18]. $95 \%$ confidence intervals $(\mathrm{CI})$ are reported as appropriate. We used generalized anxiety, and conduct and peer relationship problem scores as continuous variable in MCA as clinical cut-off scores for these conditions are not readily available for young children in India. Among the items in SCAS and SDQ, we report the items which substantially contributed to the generalized anxiety, conduct and peer relationship problems in $\mathrm{COA}$ and $\mathrm{COO}$ groups, respectively.

\section{Results}

A total of 400 orphaned children aged 12-16 years were approached from 14 orphanages of whom 396 (99.3\%) participated. Among those who participated, 199 (50.3\%) were COA and 306 (76.5\%) were aged 12 to 14 years and the median age for both boys and girls was 13 years. The proportion of boys was higher among the COA (63.5 \%) than that of girls in the $\mathrm{COO}$ group (59\%). Paternal orphans constituted nearly half of all the children sampled (51.8\%) followed by double orphans $(30.7 \%)$. The average duration of stay in an orphanage was 3.2 years (range 0 to 8 years) for $\mathrm{COA}$ and 3.6 years (range 0 to 12 years) for COO.

\section{Distribution of scores}

Table 1 shows the distribution of mean scores for generalized anxiety, conduct problem, and peer relationship problem with select variables for the orphaned children. The overall mean generalized anxiety, conduct and peer relationship problem scores were 11.1 (Standard Deviation, SD 5.2), 3.8 (SD 2.5) and 3.8 (SD 2.5) for COA and 7.6 (SD 4), 2.6 (SD 2) and 2.3 (SD 1.8) for COO, respectively. Among the COA group, the highest levels of mean generalized anxiety, conduct and peer relationship problem scores were observed among those children who had resided in an orphanage for $>3$ years and for girls. Among the $\mathrm{COO}$, the highest levels of mean generalized anxiety, conduct and peer relationship problem scores were observed among those children who had reported experiencing abuse ever.

The distribution of generalized anxiety score for both $\mathrm{COA}$ and $\mathrm{COO}$ was clustered around the younger age groups ( $p=0.001$; Fig. 1$)$. The association between generalized anxiety score with depression, conduct and peer relationship problem is shown in Fig. 2. Among both groups, generalized anxiety score increased with an increase in depression score and this association was much stronger for $\operatorname{COA}\left(R^{2}=46.2 \%\right)$ than for $\operatorname{COO}\left(R^{2}=\right.$ $21.4 \%)$. The levels of generalized anxiety and conduct and peer relationship problems were also positively associated for both the groups. However, in the COA group, 


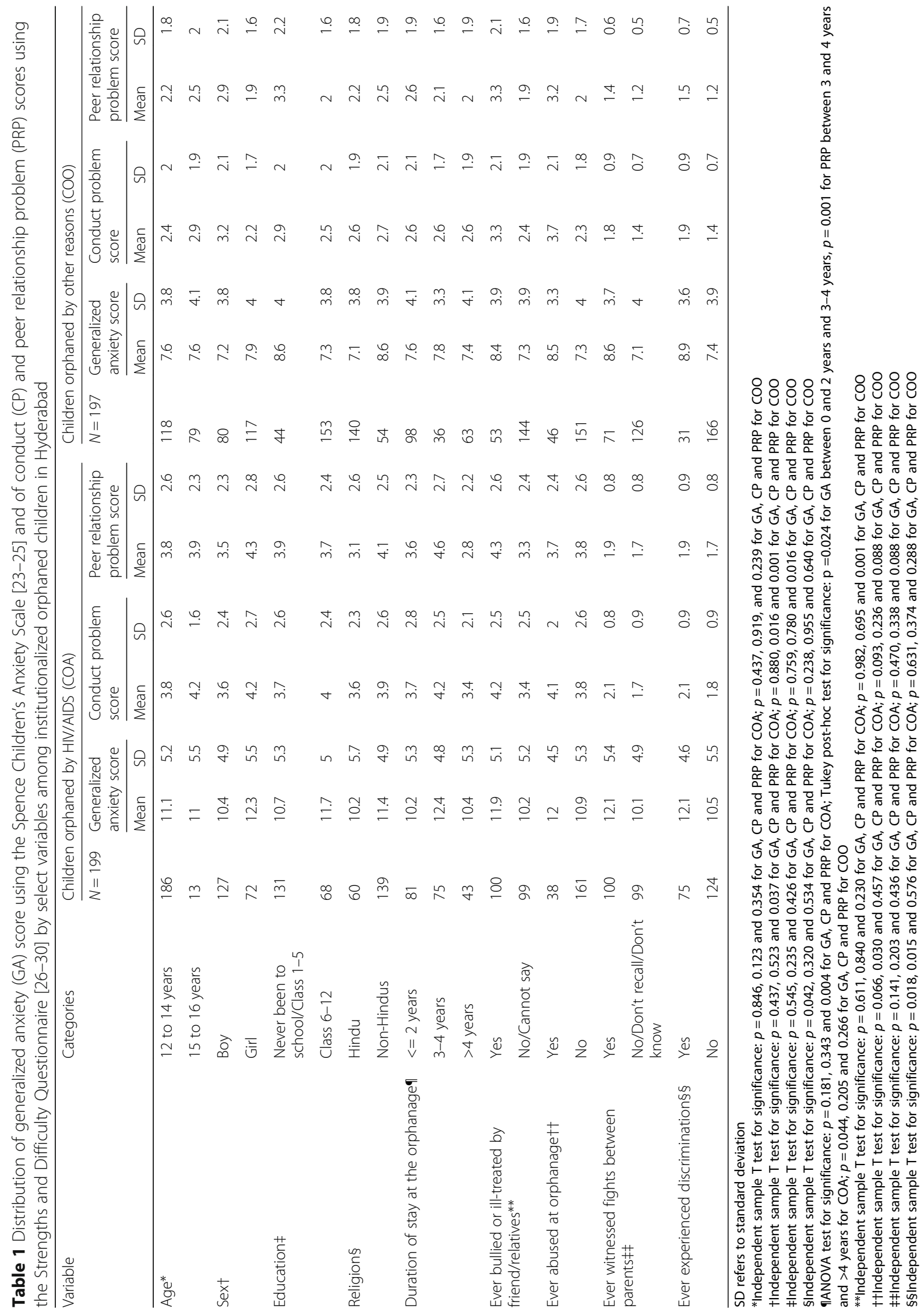




\begin{tabular}{|c|c|c|c|c|c|c|c|}
\hline & & \multicolumn{2}{|c|}{$\diamond$ Individual participants- COA } & \multicolumn{3}{|c|}{ * Individual participants- COO } & \\
\hline \multirow{2}{*}{\multicolumn{2}{|c|}{18}} & $\diamond$ & 米 & $\diamond$ & & $\diamond$ & \\
\hline & & & $\diamond$ & & & * & \\
\hline \multirow{2}{*}{\multicolumn{2}{|c|}{16}} & * & $\diamond$ & $\diamond$ & * & & \\
\hline & & 米 & * & $\diamond$ & & & \\
\hline \multicolumn{2}{|c|}{14} & 米 & $\diamond$ & $\diamond$ & * & $\diamond$ & \\
\hline \multirow{8}{*}{\multicolumn{2}{|c|}{ 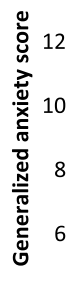 }} & 米 & $\diamond$ & 米 & $\diamond$ & * & \\
\hline & & 米 & * & * & * & * & \\
\hline & & 米 & * & 米 & * & * & \\
\hline & & * & * & 米 & 米 & 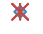 & \\
\hline & & * & 米 & 米 & * & & \\
\hline & & 米 & * & * & * & * & \\
\hline & & * & * & * & * & * & \\
\hline & & * & * & * & * & * & \\
\hline \multirow{2}{*}{\multicolumn{2}{|c|}{4}} & * & * & * & * & * & \\
\hline & & * & $\diamond$ & * & * & * & \\
\hline \multirow{2}{*}{\multicolumn{2}{|c|}{2}} & * & * & * & * & * & \\
\hline & & * & * & 米 & * & * & \\
\hline \multirow{2}{*}{\multicolumn{2}{|c|}{0}} & 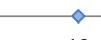 & $\diamond$ & * & * & $-*$ & 17 \\
\hline & & 12 & 13 & 14 & 15 & 16 & 17 \\
\hline
\end{tabular}

Fig. 1 Distribution of generalized anxiety scores by age using the Spence Children's Anxiety Scale [23-25] for the institutionalized orphaned children in Hyderabad. Horizontal line indicates the clinical cut-off score $>8$. COA denotes children orphaned by HIV/AIDS and COO denotes children orphaned by other reasons
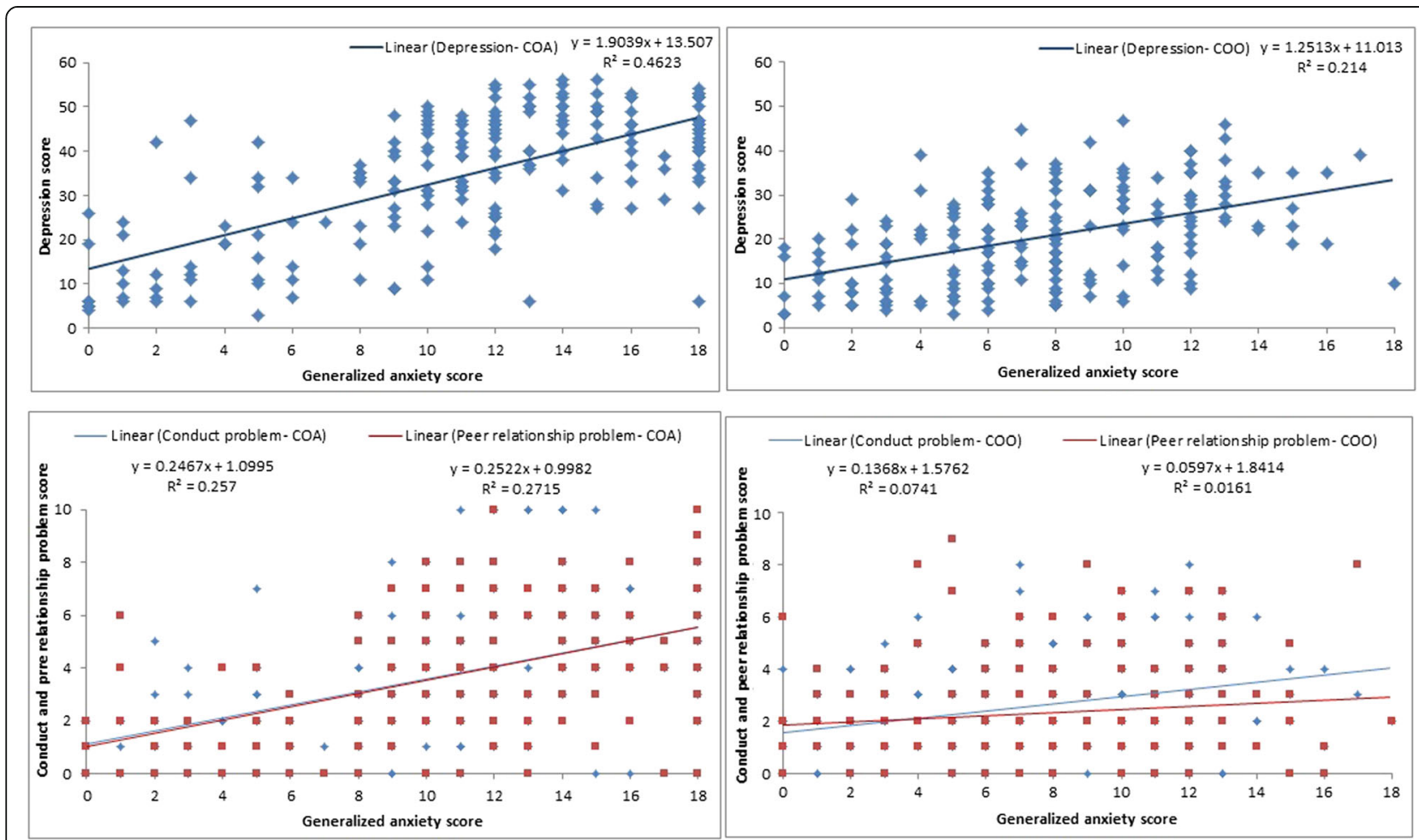

Fig. 2 Distribution of generalized anxiety using the Spence Children's Anxiety Scale [23-25] and depression, conduct and peer relationship problem scores using Strengths and Difficulties Questionnaire [26-30] for institutionalized orphaned children in Hyderabad. COA denotes children orphaned by HIV/AIDS and COO denotes children orphaned by other reasons 
generalized anxiety score increased similarly with increasing conduct (regression slope: 0.247 ) and peer relationship problem scores (regression slope: 0.252); whereas conduct problem registered a steep increase among the COO group (regression slope: 0.136) as compared to peer relationship problem (regression slope: 0.059) as the level of generalized anxiety increased. These two regression slopes were significantly different using pool error variance test $(p<0.001)$.

The overall prevalence of generalized anxiety score of $>8$ was $56.1 \%$ (95\% CI 51.1-60.9\%), and conduct problem score of $>4$ and peer relationship problem score of $>5$ was $25.3 \%$ (95\% CI 21.2-29.8\%) and $17.2 \%$ (95\% CI 13.8-21.2\%), respectively. The prevalence of generalized anxiety, conduct and peer relationship problem with these scores was significantly higher among COA-74.4 \% (95 \% CI 67.8-80.0\%; $p<0.001$ ), $33.2 \%$, (95\% CI 26.9-40.1\%; $p<0.001)$ and $27.6 \%$, (95\% CI 21.8-34.3\%; $p<0.001)$, respectively. The prevalence of these in $\mathrm{COO}$ was $37.6 \%$, (95 \% CI 31.0-44.6\%), $17.3 \%$, (95 \% CI 12.6-23.2 \%), and $6.6 \%$, (95 \% CI 3.9$11.1 \%)$, respectively.

\section{Characteristics of generalized anxiety}

Table 2 shows distribution of items on the SCAS by the type of orphan. Overall, the items that were reported the most were: I felt afraid (always, $30.8 \%$ ), I worry about things (always, $29.8 \%$ ), and when I have a problem, my heart beats really fast (always, $25.8 \%$ ). COA were more likely to report "feeling afraid, worrying about things, and worrying that something bad would happen" as compared with the $\mathrm{COO}(p<0.001)$.
Comparing boys and girls, boys were more likely to report that feeling afraid (always, $27.1 \% ; p=0.002$ ), feel that when in a problem, their heart beats really fast (always, $25.1 \% ; p=0.070$ ), and when in problem they feel shaky (always, $22.2 \%$; $p=0.173$ ), whereas more girls likely to worry about things (always, $38.6 \%$; $p=0.002$ ), and feeling afraid (always, $34.9 \%$; $p=0.002$ ).

\section{Characteristics of conduct and peer relationship problem}

Table 3 shows distribution of items on the SDQ for the study participants that measure conduct and peer relationship problems. The items that were reported the most for conduct problem were: I get very angry and often lose my temper (certainly true, $47.7 \%$ ) and I fight a lot (certainly true, $28 \%$ ). Both COA and COO reported "getting angry and often losing temper" followed by "I fight a lot" in the COA and "I usually do as I am told" in the COO group. For the peer relationship problem, the items that were reported the most were: I get on better with adults than with people of my age (certainly true, $46 \%$ ) followed by I am usually on my own (certainly true, $18.7 \%$ ). Both COA and COO were also more likely to report I get on better with adults than with people of my age (certainly true, 42.7 and $49.2 \%$ ) followed by I am usually on my own (certainly true, 27.6 and $9.6 \%)$.

\section{Determinants of generalized anxiety, conduct and peer relationship problems}

Table 4 shows the MCA for the adjusted predicted mean scores for generalized anxiety, conduct and peer relationship problem scores. As expected, depression had the highest effect on the intensity of generalized anxiety,

Table 2 Distribution of Spence Children's Anxiety Scale items [23-25] towards the burden of generalized anxiety among the orphaned children in Hyderabad (not mutually exclusive)

\begin{tabular}{|c|c|c|c|c|c|c|c|c|c|c|c|c|}
\hline \multirow[t]{2}{*}{ Item description } & \multicolumn{4}{|c|}{ Total orphans $(N=396 ; \%$ of $N)$} & \multicolumn{4}{|c|}{$\begin{array}{l}\text { Children orphaned by } \\
\text { HIV/AIDS }(N=199 ; \% \text { of } N)\end{array}$} & \multicolumn{4}{|c|}{$\begin{array}{l}\text { Children orphaned by other } \\
\text { reasons }(n=197 ; \% \text { of } N)\end{array}$} \\
\hline & Never & Some-times & Often & Always & Never & Some-times & Often & Always & Never & Some-times & Often & Always \\
\hline \multirow[t]{2}{*}{ I worry about things } & 105 & 73 & 100 & 118 & 37 & 38 & 47 & 77 & 68 & 35 & 53 & 41 \\
\hline & $(30.5)$ & $(10.8)$ & $(25.3)$ & $(29.8)$ & $(18.6)$ & $(19.1)$ & $(23.6)$ & $(38.7)$ & $(34.5)$ & $(17.8)$ & $(26.9)$ & $(20.8)$ \\
\hline \multirow{2}{*}{$\begin{array}{l}\text { When I have a problem, } \\
\text { I get a funny feeling in } \\
\text { my stomach }\end{array}$} & 85 & 104 & 137 & 70 & 30 & 48 & 72 & 49 & 55 & 56 & 65 & 21 \\
\hline & $(21.5)$ & $(26.3)$ & (34.6) & $(17.7)$ & $(15.1)$ & $(24.1)$ & $(36.2)$ & (24.6) & $(27.9)$ & $(28.4)$ & $(33.0)$ & $(10.7)$ \\
\hline \multirow[t]{2}{*}{ I feel afraid } & 88 & 78 & 108 & 122 & 30 & 22 & 53 & 94 & 58 & 56 & 55 & 28 \\
\hline & $(22.2)$ & $(19.7)$ & $(27.3)$ & (30.8) & (15.1) & $(11.1)$ & $(26.6)$ & $(47.2)$ & $(29.4)$ & $(28.4)$ & $(27.9)$ & $(14.2)$ \\
\hline \multirow{2}{*}{$\begin{array}{l}\text { When I have a problem, } \\
\text { my heart beats really fast }\end{array}$} & 46 & 100 & 148 & 102 & 16 & 47 & 60 & 76 & 30 & 53 & 88 & 26 \\
\hline & (11.6) & $(25.3)$ & (37.4) & $(25.8)$ & $(8.0)$ & $(23.6)$ & $(30.2)$ & $(38.2)$ & $(15.2)$ & $(26.9)$ & $(44.7)$ & $(13.2)$ \\
\hline \multirow{2}{*}{$\begin{array}{l}\text { I worry that something } \\
\text { bad will happen to me }\end{array}$} & 141 & 90 & 76 & 89 & 56 & 34 & 32 & 77 & 85 & 56 & 44 & 12 \\
\hline & (35.6) & $(22.7)$ & $(19.2)$ & $(22.5)$ & $(28.1)$ & $(17.1)$ & $(16.1)$ & $(38.7)$ & $(43.1)$ & $(28.4)$ & $(22.3)$ & (6.1) \\
\hline \multirow{2}{*}{$\begin{array}{l}\text { When I have a problem, } \\
\text { I feel shaky }\end{array}$} & 80 & 103 & 129 & 84 & 24 & 52 & 53 & 70 & 56 & 51 & 76 & 14 \\
\hline & $(20.2)$ & $(26.0)$ & (32.6) & $(21.2)$ & $(12.1)$ & $(26.1)$ & (26.6) & $(35.2)$ & $(28.4)$ & $(25.9)$ & (38.6) & (7.1) \\
\hline
\end{tabular}


Table 3 Distribution of Strengths and Difficulties Questionnaire [26-30] items towards the burden of conduct and peer relationship problem among the orphaned children in Hyderabad (not mutually exclusive)

\begin{tabular}{|c|c|c|c|c|c|c|c|c|c|}
\hline \multirow[t]{2}{*}{ Item description } & \multicolumn{3}{|c|}{ Total orphans $(N=396 ; \%$ of $N)$} & \multicolumn{3}{|c|}{$\begin{array}{l}\text { Children orphaned by } \\
\text { HIV/AIDS ( } N=199 ; \% \text { of } N)\end{array}$} & \multicolumn{3}{|c|}{$\begin{array}{l}\text { Children orphaned by other } \\
\text { reasons }(N=197 ; \% \text { of } N)\end{array}$} \\
\hline & $\begin{array}{l}\text { Not } \\
\text { true }\end{array}$ & $\begin{array}{l}\text { Somewhat } \\
\text { true }\end{array}$ & $\begin{array}{l}\text { Certainly } \\
\text { true }\end{array}$ & $\begin{array}{l}\text { Not } \\
\text { true }\end{array}$ & $\begin{array}{l}\text { Somewhat } \\
\text { true }\end{array}$ & $\begin{array}{l}\text { Certainly } \\
\text { true }\end{array}$ & $\begin{array}{l}\text { Not } \\
\text { true }\end{array}$ & $\begin{array}{l}\text { Somewhat } \\
\text { true }\end{array}$ & $\begin{array}{l}\text { Certainly } \\
\text { true }\end{array}$ \\
\hline \multicolumn{10}{|l|}{ Conduct problem } \\
\hline \multirow{2}{*}{$\begin{array}{l}\text { I get very angry and often } \\
\text { lose my temper }\end{array}$} & 104 & 103 & 189 & 32 & 44 & 123 & 72 & 59 & 66 \\
\hline & (26.3) & $(26.0)$ & $(47.7)$ & $(16.1)$ & $(22.1)$ & $(61.8)$ & $(36.5)$ & $(29.9)$ & (33.5) \\
\hline \multirow[t]{2}{*}{ I usually do as I am told } & 260 & 67 & 69 & 140 & 24 & 35 & 120 & 43 & 34 \\
\hline & (65.7) & $(16.9)$ & $(17.4)$ & (70.4) & $(12.1)$ & $(17.6)$ & $(60.9)$ & $(21.8)$ & $(17.3)$ \\
\hline \multirow[t]{2}{*}{ I fight a lot } & 185 & 100 & 111 & 64 & 47 & 88 & 121 & 53 & 23 \\
\hline & $(46.7)$ & $(25.3)$ & $(28.0)$ & $(32.2)$ & $(23.6)$ & $(44.2)$ & $(61.4)$ & $(26.9)$ & $(11.7)$ \\
\hline \multirow{2}{*}{$\begin{array}{l}\text { I am often accused of } \\
\text { lying or cheating }\end{array}$} & 270 & 58 & 68 & 123 & 39 & 37 & 147 & 19 & 31 \\
\hline & $(68.2)$ & $(14.6)$ & $(17.2)$ & $(61.8)$ & $(19.6)$ & $(18.6)$ & $(74.6)$ & (9.6) & $(15.7)$ \\
\hline \multirow[t]{2}{*}{ I take things that are not mine } & 348 & 22 & 26 & 174 & 9 & 16 & 174 & 13 & 10 \\
\hline & $(87.9)$ & (5.6) & $(6.6)$ & $(87.4)$ & $(4.5)$ & $(8.0)$ & $(88.3)$ & (6.6) & $(5.1)$ \\
\hline \multicolumn{10}{|l|}{ Peer relationship problem } \\
\hline \multirow[t]{2}{*}{ I am usually on my own } & 253 & 69 & 74 & 99 & 45 & 55 & 154 & 24 & 19 \\
\hline & (63.9) & $(17.4)$ & $(18.7)$ & $(49.7)$ & $(22.6)$ & $(27.6)$ & $(78.2)$ & $(12.2)$ & (9.6) \\
\hline \multirow[t]{2}{*}{ I have one good friend or more } & 278 & 87 & 31 & 109 & 66 & 24 & 169 & 21 & 7 \\
\hline & $(70.2)$ & $(22.0)$ & $(7.8)$ & $(54.8)$ & $(33.2)$ & $(12.1)$ & $(85.8)$ & $(10.7)$ & (3.6) \\
\hline \multirow{2}{*}{$\begin{array}{l}\text { Other people of my age generally } \\
\text { like me }\end{array}$} & 248 & 113 & 35 & 100 & 77 & 22 & 148 & 36 & 13 \\
\hline & (62.6) & $(28.5)$ & (8.8) & (50.3) & $(38.7)$ & $(11.1)$ & $(75.1)$ & (18.3) & (6.6) \\
\hline \multirow{2}{*}{$\begin{array}{l}\text { Other children or young people } \\
\text { tease or harass me }\end{array}$} & 266 & 77 & 53 & 103 & 57 & 39 & 163 & 20 & 14 \\
\hline & $(67.2)$ & $(19.4)$ & $(13.4)$ & (51.8) & (28.6) & (19.6) & $(82.7)$ & $(10.2)$ & (7.1) \\
\hline \multirow{2}{*}{$\begin{array}{l}\text { I get on better with adults } \\
\text { than with people of my age }\end{array}$} & 101 & 113 & 182 & 52 & 62 & 85 & 49 & 51 & 97 \\
\hline & $(25.5)$ & $(28.5)$ & $(46.0)$ & $(26.1)$ & $(31.2)$ & $(42.7)$ & $(24.9)$ & $(25.9)$ & $(49.2)$ \\
\hline
\end{tabular}

conduct and peer relationship problems with a beta value of $0.477,0.379$ and 0.453 , respectively. Being an AIDS orphan and being a girl had the most impact on generalized anxiety ( 0.100 and 0.115 , respectively) as compared with their effect on conduct or peer relationship problems. Having witnessed their parents fight had a relatively higher impact on the conduct problem (0.142) whereas duration of stay in orphanage and ever being bullied had the most impact on the peer relationship problems (0.153 and 0.134$)$ respectively.

\section{Discussion}

We found a significantly higher proportion of AIDS orphans dealing with generalized anxiety, conduct and peer relationship problem as compared with orphans due to other reasons in the institutionalized orphans in the city of Hyderabad.

A little over half of the children in this study had a generalized anxiety score of $>8$, and $75 \%$ of COA and $38 \%$ of $\mathrm{COO}$ were identified with this score. Generalized anxiety is often underestimated as it remains undiagnosed owing to the internalized nature of its symptoms [7], and is associated with substantial negative effects on social, emotional and academic success of those affected [8]. There are mixed reports from previous research on anxiety in COA with some studies reporting a high level of anxiety $[4,9-12]$, and some lower levels $[13,33]$. The mean generalized anxiety scores in our study were higher among girls, particularly COA, than boys. Furthermore, girls were more likely to report being worried about things and feeling afraid, which is consistent with previous research which emphasizes that factors like personal, physical, biological, socio-cultural, and coping mechanisms could influence anxiety levels among girls [34-36]. These findings point to the need for more research to understand the dynamics of gender and its role in influencing mental health outcomes among children and adolescents in India. In the meanwhile, these findings can be used to develop genderspecific social support programs that address the emotional needs of orphans.

The levels of generalized anxiety and depression revealed a positive association in both the groups, with 
Table 4 Multiple classification analysis for effect of selected variables on generalized anxiety, conduct and peer relationship problem for the institutionalized orphaned children in Hyderabad

\begin{tabular}{|c|c|c|c|c|c|c|c|c|c|c|c|}
\hline \multirow[t]{3}{*}{ Variable } & \multirow[t]{3}{*}{ Categories } & \multirow[t]{3}{*}{$N=396$} & \multicolumn{9}{|c|}{ Adjusted predicted Mean } \\
\hline & & & \multicolumn{3}{|c|}{$\begin{array}{l}\text { Generalized } \\
\text { anxiety }\end{array}$} & \multicolumn{3}{|c|}{$\begin{array}{l}\text { Conduct } \\
\text { problem }^{\mathrm{a}}\end{array}$} & \multicolumn{3}{|c|}{$\begin{array}{l}\text { Peer relationship } \\
\text { problemb }^{b}\end{array}$} \\
\hline & & & Mean & Beta & $P$ value & Mean & Beta & $P$ value & Mean & Beta & $P$ value \\
\hline \multirow[t]{2}{*}{ Age } & 12 to 14 years & 304 & 9.55 & 0.077 & 0.086 & 3.21 & 0.010 & 0.836 & 3.11 & 0.044 & 0.324 \\
\hline & 15 to 16 years & 92 & 8.65 & & & 3.26 & & & 2.87 & & \\
\hline \multirow[t]{2}{*}{ Sex } & Boy & 207 & 8.80 & 0.115 & 0.005 & 3.35 & 0.057 & 0.196 & 3.13 & 0.033 & 0.423 \\
\hline & Girl & 189 & 9.93 & & & 3.08 & & & 2.97 & & \\
\hline \multirow[t]{2}{*}{ Child orphaned by HIV/AIDS } & Yes & 199 & 9.83 & 0.100 & 0.047 & 3.30 & 0.034 & 0.530 & 3.14 & 0.037 & 0.462 \\
\hline & No & 197 & 8.85 & & & 3.14 & & & 2.97 & & \\
\hline \multirow[t]{3}{*}{ Duration of stay at the orphanage } & $\leq 2$ years & 179 & 9.00 & 0.103 & 0.047 & 3.12 & 0.076 & 0.225 & 3.08 & 0.153 & 0.001 \\
\hline & 3 to 4 years & 111 & 10.15 & & & 3.51 & & & 3.50 & & \\
\hline & $>4$ years & 106 & 9.07 & & & 3.10 & & & 2.54 & & \\
\hline \multirow[t]{2}{*}{ Witnessed fights between parents } & Yes & 171 & 9.99 & 0.116 & 0.005 & 3.60 & 0.142 & 0.001 & 3.23 & 0.066 & 0.111 \\
\hline & No/do not remember & 225 & 8.85 & & & 2.93 & & & 2.92 & & \\
\hline \multirow{2}{*}{$\begin{array}{l}\text { Ever bullied or ill-treated by } \\
\text { friend/relatives }\end{array}$} & Yes & 153 & 9.53 & 0.031 & 0.530 & 3.45 & 0.078 & 0.144 & 3.45 & 0.134 & 0.007 \\
\hline & No/ Cannot say & 243 & 9.22 & & & 3.08 & & & 2.80 & & \\
\hline \multirow[t]{2}{*}{ Ever experienced discrimination } & Yes & 106 & 9.57 & 0.028 & 0.571 & 3.28 & 0.014 & 0.795 & 3.09 & 0.009 & 0.849 \\
\hline & No & 290 & 9.26 & & & 3.20 & & & 3.04 & & \\
\hline \multirow[t]{3}{*}{ Depression score ${ }^{c}$} & $<=$ mean score & 199 & 7.01 & 0.477 & $<0.001$ & 2.34 & 0.379 & $<0.001$ & 2.00 & 0.453 & $<0.001$ \\
\hline & $>$ mean score & 197 & 11.70 & & & 4.11 & & & 4.12 & & \\
\hline & Full model & 396 & & 0.379 & $<0.001$ & & 0.252 & $<0.001$ & & 0.354 & $<0.001$ \\
\hline
\end{tabular}

${ }^{a}$ The conduct problem scale from the Strengths and Difficulties Questionnaire was used to assess conduct problem in children. The possible scores ranged from 0 to 10 , and a score of 4 was considered borderline and scores 5-10 are considered abnormal for conduct problem

${ }^{\mathrm{b}}$ The peer relationship problems scale from the Strengths and Difficulties Questionnaire was used to assess peer relationship problems in children. The possible score ranged from 0 to 10, and a scores of 4-5 are considered borderline and scores 6-10 are considered abnormal for peer relationship problem

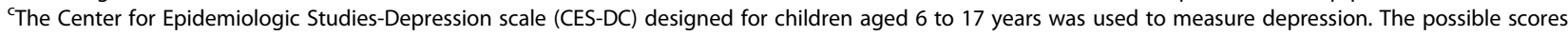
ranged from 0 to 60 , and A CES-DC score of 15 or higher has previously been considered suggestive of significant level of depressive symptoms in children and adolescents

COA exhibiting a strong positive correlation. Although depression and anxiety have historically been seen as distinct conditions, the two disorders are not mutually exclusive and often coexist to varying degrees in the same individual $[37,38]$, and patients with co-morbid depression and anxiety frequently also have poorer prognosis and a lower response to treatment [37, 38]. This study finding has a strong intervention implication for mental health outcomes among orphans as the strategies aiming to improve child mental health under the current child mental health policy and school mental health policy should aim to look into the interplay between anxietydepression and design appropriate interventions [1].

In this study, the mean scores for conduct and peer relationship problem were significantly higher among those who were bullied or ill-treated by their friends or relatives and those who experienced discrimination as an orphan. This was more explicitly visible in the COA than the $\mathrm{COO}$, with a significantly higher proportion of COA identified with conduct and peer relationship problem scores $>4$ and $>5$, respectively. The relationship between parental death due to AIDS on children's conduct and peer relationship problems is well documented [39-41]. The possibility of psychopathic behavior among children raised without supervision relating to unknown psychosocial effects of orphanhood has been noted previously $[11,42]$. In this study, the orphaned children reported getting very angry often and fighting frequently; and most of the COA reported having just one or no friends at all and expressed concerns that their peers generally do not like them. The majority also noted that they got along well with older people rather than their peers. These finding support previous and growing evidence which suggest that orphanhood by AIDS is significantly associated with increased peer relationship problems $[34,43]$. It is reasoned that it is cumulative effects of HIV/AIDS related stigma and discriminations that underline the higher scores of peer relationship problems in COA over COO [44]. The main implication of these findings is the need to recognize and address the increased risk of conduct and peer relationship problem disturbances in these children by the government 
agencies, NGO's, and by health professionals working with HIV/AIDS affected children.

The strength of this study is that this is the largest study to date that has compared psychological issues among $\mathrm{COA}$ and $\mathrm{COO}$ living in orphanages. With twice the prevalence of generalized anxiety and conduct problems, and four times higher prevalence of peer relationship problems among the COA than $\mathrm{COO}$, it is clear that a parental death due to HIV/AIDS has far reaching mental health implications than parental death due to any other reason. There are some limitations of this study to be taken into consideration. As validated mental health scales for children are not readily available in India, we used SCAS which has been used in various cultures. However, all psychological measures should be interpreted with caution in different cultures. We, therefore, used continuous scale and not the clinical cut-off score reflecting western norms as it may be inappropriate for this study population. Misreporting of the parental cause of death could be a limitation as it was documented based on information provided by the child or the NGO staff. It was not possible to confirm the parental cause of death. The crosssectional nature of these data does not allow temporal or causal explanations as these data do not allow comment on psychological issues in these children prior to them being orphaned.

Psychosocial needs of children affected by AIDS, especially orphans, are most often neglected in the program design. There is a lack of specific program or policy in India to address the growing numbers of COA [45, 46]. Already four years into the phase IV of the national AIDS control program, interventions for children orphaned by AIDS are conspicuous by their absence [47]. There is clearly a need for specific interventions based on local evidence to have an effective response for these vulnerable groups through the national AIDS program, and as part of the child mental health policy, school mental health policy, and mental health policies for disabled at the community level [1].

\section{Conclusions}

In conclusion, this study has contributed to building an evidence and further work is neededto understand longterm impacts of parental death on children. The urgent need to address the poor mental health of orphans, in particular the AIDS orphans, in India is highlighted.

\footnotetext{
Acknowledgments

The authors wish to thank the children who participated in this study and the staff of orphanages. We thank Ms. Ophir Rani, certified child counselor, for training staff on handling children on sensitive issues. The views expressed in this paper are those of the authors and do not necessarily reflect the views of the funding agency, organisations that facilitated this study, or the institutions employing the authors.
}

SGPK was supported by a research fellowship under the Wellcome Trust Capacity Strengthening Strategic Award to the Public Health Foundation of India and a consortium of UK universities (Grant: WT084754/Z/08/Z).

\section{Funding}

SGPK was supported by a research fellowship under the Wellcome Trust Capacity Strengthening Strategic Award to the Public Health Foundation of India and a consortium of UK universities (Grant: WT084754/Z/08/Z).

\section{Availability of data and materials}

Access to the local database is available upon request to the corresponding author.

\section{Authors' contributions}

SGPK managed data collection. SGPK and RD wrote the first draft of manuscript. SGPK and GAK performed analysis. All authors contributed to design, interpretation and paper writing, and approved the final version of manuscript.

\section{Competing interests}

The authors declare that they have no competing interest.

\section{Consent for publication}

Not applicable.

\section{Ethical approval and consent to participate}

The study protocol was approved by the Ethics Committee of the Public Health Foundation of India, New Delhi. For children aged 12 to 14 years, child assent was obtained along with written informed consent from the care-giver/guardian; written informed consent was obtained from children 15-16 years of age.

Received: 18 November 2015 Accepted: 12 September 2016

Published online: 21 September 2016

\section{References}

1. Ministry of Health and Family Welfare. Government of India. The Draft Mental Health Care Bill, 2011. New Delhi; 2011.

2. Shah I. Prevalence of orphans among HIV infected children: A preliminary study from a pediatric HIV centre in Western India. J Trop Pediatr. 2008;54:258-60.

3. Boyd CP, Kostanski M, Gullone E, Ollendick TH, Shek DT. Prevalence of anxiety and depression in Australian adolescents: Comparisons with worldwide data. J Genet Psychol. 2000;161:479-92.

4. Atwine B, Cantor-Braae E, Bajunirwe F. Psychological distress among AIDS orphans in rural Uganda. Soc Sci Med. 2005;61(3):555-64.

5. Costello EJ, Mustillo S, Erkanli A, Keeler G, Angold A. Prevalence and development of psychiatric disorders in childhood and adolescence. Arch Gen Psychiatry. 2003;60:837-44

6. Tomb M, Hunter L. Prevention of anxiety in children and adolescents in a school setting: The role of school-based practitioners. Child Sch. 2004;26:87-101.

7. Young L, Ansell N. Young AIDS migrants in South Africa: policy implications for empowering children. AIDS Care. 2003;15(3):337-45.

8. Tsiwo-Chigubi G. Exploring self-esteem of orphans whose parents died of HIV/AIDS; examined through the extended family/kinship caregivers' economic wellbeing, social support and child-rearing practices in Zimbabwe. Diss Abstr Int. 2005;62:1301

9. Cluver L, Gardner F, Operario D. Poverty and psychological health among AIDSorphaned children in Cape Town, South Africa. AIDS Care. 2009:21(6):732-41.

10. Boyes ME, Cluver LD. Relationships amongst HIV/AIDS-orphanhood, stigma, and symptoms of anxiety and depression in South African youth: A longitudinal investigation using a path analysis framework. Clin Psychol Sci. 2013:1(3):323-30.

11. Makame V, Ani C, Grantham-McGregor S. Psychological well-being of orphans in Dar El Salaam, Tanzania. Acta Paediatr. 2002;91(4):459-65.

12. Nyamukapa CA, Gregson S, Lopman B, Saito S, Watts HJ, Monasch R, et al. HIV-Associated orphanhood and children's psychosocial distress: Theoretical framework tested with data from Zimbabwe. Am J Public Health. 2008;98(1):133-41.

13. Cluver L, Gardner F, Operario D. Psychological distress amongst AIDS orphaned children in urban South Africa. J Child Psychol Psychiatry. 2007:48(8):755-63. 
14. George CR, Mucheuki C, Govender K, Quinlan T. Psychosocial and health risk outcomes among orphans and non-orphans in mixed households in KwaZulu-Natal, South Africa. Afr J AIDS Res. 2015;14(4):323-31.

15. Hongfei DU, Xiaoming LI, Traci LW, Peilian CH, Junfeng ZH, Guoxiang ZH. Links between Mental and Behavioral Health among Children Affected by HIV/AIDS and Teachers' Assessments of Children. AIDS Care. 2015;27(7):876.

16. Cohen MH. Rwandan Youth With HIV: Impact of Mental Health on Adherence. 143rd APHA Annual Meeting and Expo. Chicago: APHA; 2015.

17. Rao R, Sagar R, Kabra SK, Lodha R. Psychiatric morbidity in HIV-infected children. AIDS Care. 2007;19:828-33.

18. Kumar SGP, Dandona R, Kumar GA, Ramgopal SP, Dandona L. Depression among AIDS-orphaned children higher than among other orphaned children in southern India. Int J Ment Heal Syst. 2014;8(1):13.

19. UNAIDS. 2004 report on the global AIDS epidemic. Focus: AIDS and orphans: a tragedy unfolding. New York: Joint United Nations Programme on HIV/AIDS (UNAIDS); 2004.

20. UNICEF. Information by country: India. http://www.unicef.org/infobycountry/ india.html. Accessed 17 June 2016.

21. International Institute for Population Sciences (IIPS) and Macro International. National Family Health Survey (NFHS-3), 2005-06: India. Mumbai: International Institute for Population Sciences; 2007.

22. UNICEF. The framework for the protection, care and support of orphans and vulnerable children living in a world with HIV and AIDS. Geneva: UNICEF; 2004.

23. Spence SH, Barrett PM, Turner CM. Psychometric properties of the Spence Children's Anxiety Scale with young adolescents. J Anxiety Disord. 2003; 17(6):605-25.

24. Spence SH. Structure of anxiety symptoms among children: a confirmatory factor-analytic study. J Abnorm Psychol. 1997;106(2):280-97.

25. Spence $\mathrm{SH}$. A measure of anxiety symptoms among children. Behav Res Ther. 1998;36(5):545-66.

26. Goodman R. The Strengths and Difficulties Questionnaire: a research note. J Child Psychol Psychiatry. 1997;38(5):581-6.

27. Goodman R. Psychometric properties of the strengths and difficulties questionnaire. J Am Acad Child Adolesc Psychiatry. 2001:40(11):1337-45.

28. Goodman A, Lamping DL, Ploubidis GB. When to use broader internalising and externalising subscales instead of the hypothesised five subscales on the Strengths and Difficulties Questionnaire (SDQ): data from British parents, teachers and children. J Abnorm Child Psychol. 2010:38:1179-91.

29. Goodman A, Goodman R. Strengths and Difficulties Questionnaire scores and mental health in looked after children. Br J Psychiatry. 2012;200(5):426-7.

30. Bourdon KH, Goodman R, Rae DS, Simpson G, Koretz DS. The Strengths and Difficulties Questionnaire: U.S. normative data and psychometric properties. J Am Acad Child Adolesc Psychiatry. 2005;44(6):557-64.

31. Fisher RA. Statistical Methods for Research Workers. Edinburgh, United Kingdom: Oliver \& Boyd; 1925.

32. Tukey J. Comparing Individual Means in the Analysis of Variance. Biometrics. 1949;5(2):99-114.

33. Wild L, Flisher A, Laas S, Robertson B. Psychosocial adjustment of adolescents orphaned in the context of HIV/AIDS. Melbourne, Australia: Poster presented at the International Society for the Study of Behavioral Development Biennial Meeting; 2006.

34. Wittchen HU, Stein MB, Kessler RC. Social fears and social phobia in a community sample of adolescents and young adults: Prevalence, risk factors and co-morbidity. Psychol Med. 1999:29:309-23.

35. Beesdo K, Knappe S, Pine DS. Anxiety and anxiety disorders in children and adolescents: developmental issues and implications for DSM-V. Pediatr Clin North Am. 2009;32:483-524.

36. Zhao J, Li X, Barnett D, Lin X, Fang X, Zhao G, et al. Parental Loss, Trusting Relationship with Current Caregivers and Psychosocial Adjustment among Children Affected by AIDS in China. Psychol Health Med. 2011;16(4):437-49.

37. Clayton PJ. The comorbidity factor: Establishing the primary diagnosis in patients with mixed symptoms of anxiety and depression. J Clin Psychiatry. 1990:51 Suppl 11:35-9.

38. Lydiard RB. Coexisting depression and anxiety: Special diagnostic and treatment issues. J Clin Psychiatry. 1991;52 Suppl 6:48-54.

39. Doku PN. Parental HIV/AIDS status and death, and children's psychological wellbeing. Int J Ment Heal Syst. 2009;3:26.

40. Lin X, Zhao G, Li X, Stanton B, Zhang L, Hong Y, et al. Perceived HIV stigma among children in a high HIV-prevalence area in central China: beyond the parental HIV-related illness and death. AIDS Care. 2010;22(5):545-55.
41. Kaggwa EB, Hindin MJ. The psychological effect of orphanhood in a matured HIV epidemic: An analysis of young people in Mukono, Uganda. Soc Sci Med. 2010;70:1002-10.

42. Musisi S, Kinyanda E. Emotional and behavioural disorders in HIV seropositive adolescents in urban Uganda. East Afr Med J. 2009;86(1):16-24.

43. Nyambedha EO, Wandibba S, Aagaard-Hansen J. Changing Patterns of Orphan Care Due to the HIV Epidemic in Western Kenya. Soc Sci Med. 2003;57(2):301-12.

44. Cluver L, Orkin M. Cumulative risk and AIDS-orphanhood: interactions of stigma, bullying and poverty on child mental health in South Africa. Soc Sci Med. 2009;69(8):1186-93.

45 Kumar A. AIDS orphans and vulnerable children in India: problems, prospects, and concerns. Soc Work Public Health. 2012;27:205-12.

46 UNAIDS. Children on the Brink 2002: A Joint Report on Orphan Estimates and Program. New York: Joint United Nations Programme on HIV/AIDS (UNAIDS); 2003. http://data.unaids.org/topics/young-people/ childrenonthebrink_en.pdf.

47 National AIDS Control Organization. National AIDS Control Programme: NACP- IV Components. Ministry of Health and Family Welfare, Government of India. New Delhi: NACO; 2012. http://www.naco.gov.in/nacp-ivcomponents.

\section{Submit your next manuscript to BioMed Central and we will help you at every step:}

- We accept pre-submission inquiries

- Our selector tool helps you to find the most relevant journal

- We provide round the clock customer support

- Convenient online submission

- Thorough peer review

- Inclusion in PubMed and all major indexing services

- Maximum visibility for your research

Submit your manuscript at www.biomedcentral.com/submit
) Biomed Central 